\section{Community-acquired Group B streptococcal meningitis in adults}

Dear Editor

We were somewhat surprised that the recent review of community-acquired Group B streptococcal meningitis in adults by van Kassel et al. ${ }^{1}$ contained no reference to recent work implicating foodborne transmission, particularly from raw or undercooked fish, as an important mode of acquisition of this condition in some parts of the world. The first evidence for this came from a large outbreak of invasive Group B streptococcal (GBS) infection, primarily bacteraemia, septic arthritis and meningitis, in Singapore in $2015^{2}$. Both epidemiological and molecular evidence suggested that these infections, caused by GBS of serotype III, subtype 4 (serotype III-4), multilocus sequence type (MLST) 283 (ST283), were associated with the consumption of raw, farmed freshwater fish. ${ }^{3,4}$ GBS are well-known primary pathogens in fish. ${ }^{5}$ More recently it has been shown that this lineage is actually widespread amongst both human isolates of GBS in SE Asia and fish isolates both from Asia and Brazil. GBS is now a not uncommon cause of meningitis in adults in countries such as the Lao People's Democratic Republic; ${ }^{6}$ in addition, earlier reports had already noted an increase in the incidence of adult GBS meningitis in both Hong Kong and Singapore, including many cases subsequently confirmed as being caused by ST283. ${ }^{7,8}$ It thus appears possible that an extensive but previously unrecognised outbreak of invasive GBS disease associated with the consumption of raw or undercooked farmed fish, a common practice in some regions, may have been going on for several decades. ${ }^{8}$

We feel that the failure to mention these observations, which include 60 cases of adult meningitis and could fundamentally change the way in which we view the epidemiology of adult GBS disease, was an unfortunate omission in a review of adult community-acquired GBS meningitis.

Yours sincerely

\section{References}

1. van Kassel MN, van Haeringen KJ, Brouwer MC, Bijlsma MW, van de Beek D. Community-acquired Group B streptococcal meningitis in adults. J Infect 2020;80:255-60.

2. Kalimuddin S, Chen SL, Lim CTK, Koh TH, Tan TY, Kam M, et al. 2015 Epidemic of severe Streptococcus agalactiae Sequence Type 283 infections in Singapore associated with the consumption of raw freshwater fish: a detailed analysis of clinical, epidemiological, and bacterial sequencing data. Clin Infect Dis 2017;64(suppl_2):S145-SS52.

3. Tan S, Lin Y, Foo K, Koh HF, Tow C, Zhang Y, et al. Group B Streptococcus Serotype III Sequence Type 283 bacteremia associated with consumption of raw fish, Singapore. Emerg Infect Dis 2016;22:1970-3.
4. Rajendram P, Mar Kyaw W, Leo YS, Ho H, Chen WK, Lin R, et al. Group B Streptococcus Sequence Type 283 disease linked to consumption of raw fish, Singapore. Emerg Infect Dis 2016;22:1974-7.

5. Chen SL. Genomic insights into the distribution and evolution of Group B streptococcus. Front Microbiol 2019;10:1447 doi: 10:3389/fmicb.2019.01447.

6. Dubot-Pérès A, Mayxay M, Phetsouvanh R, Lee SJ, Rattanavong S, Vongsouvath M, Davong V, Chansamouth V, Phommasone K, Moore C, Dittrich S, Lattana O, Sirisouk J, Phoumin P, Panyanivong P, Sengduangphachanh A, Sibounheuang B, Chanthongthip A, Simmalavong M, Sengdatka D, Seubsanith A, Keoluangkot V, Phimmasone P, Sisout K, Detleuxay K, Luangxay K, Phouangsouvanh I, Craig SB, Tulsiani SM, Burns M-A, Dance DAB, Blacksell SD, de Lamballerie X, Newton PN. Revisiting management of central nervous system infections in Southeast Asia. Emerg Infect Dis 2019;25:898-910.

7. Wilder-Smith E, Chow KM, Kay R, Ip M, Tee N. Group B streptococcal meningitis in adults: recent increase in Southeast Asia. Aust N Z J Med 2000;30(4):462-5.

8. Barkham T, Zadoks RN, Azmai MNA, Baker S, Bich VTN, Chalker V, et al. One hypervirulent clone, sequence type 283, accounts for a large proportion of invasive Streptococcus agalactiae isolated from humans and diseased tilapia in Southeast Asia. PLoS Negl Trop Dis 2019;13(6):e0007421.

DAB Dance* Lao-Oxford-Mahosot Hospital-Wellcome Trust Research Unit, Mahosot Hospital, Vientiane, Lao Democratic People's Republic Centre for Tropical Medicine and Global Health, Nuffield Department of Medicine, University of Oxford, Oxford, United Kingdom Faculty of Infectious and Tropical Diseases, London School of Hygiene and Tropical Medicine, London, United Kingdom

RN Zadoks University of Sydney, Sydney, Australia

M. Luangraj Lao-Oxford-Mahosot Hospital-Wellcome Trust Research Unit, Mahosot Hospital, Vientiane, Lao Democratic People's Republic

A Simpson

Lao-Oxford-Mahosot Hospital-Wellcome Trust Research Unit, Mahosot Hospital, Vientiane, Lao Democratic People's Republic Centre for Tropical Medicine and Global Health, Nuffield Department of Medicine, University of Oxford, Oxford, United Kingdom

SL Chen Department of Medicine, Yong Loo Lin School of Medicine, National University of Singapore, Singapore Infectious Diseases Group, Genome Institute of Singapore, Singapore

T Barkham Department of Laboratory Medicine, Tan Tock Seng Hospital, Singapore

*Corresponding author. E-mail address: david.d@tropmedres.ac (D. Dance)

Accepted 9 March 2020 